九州大学学術情報リポジトリ

Kyushu University Institutional Repository

\title{
Auxin Induces Growth of Stem Excised from Growing Shoot of Cooled Tulip Bulbs
}

Saniewski, Marian

Research Institute of Pomology and Floriculture, Poland

Okubo, Hiroshi

Faculty of Agriculture, Kyushu University

Miyamoto, Kensuke

Osaka Prefecuture University

Ueda, Junichi

Osaka Prefecuture University

https://doi.org/10.5109/4661

出版情報: 九州大学大学院農学研究院紀要. 50 (2)，pp.481-488，2005-10-01. Faculty of Agriculture, Kyushu University

バージョン：

権利関係 : 
J. Fac. Agr., Kyushu Univ., 50 (2), 481-488 (2005)

\title{
Auxin Induces Growth of Stem Excised from Growing Shoot of Cooled Tulip Bulbs
}

\author{
Marian SANIEWSKI ${ }^{1 *}$, Hiroshi OKUBO, Kensuke MIYAMOTO \\ and Junichi UEDA ${ }^{2}$
}

\author{
Laboratory of Horticultural Science, Division of Agricultural Botany, Department of Plant Resources, \\ Faculty of Agriculture, Kyushu University, Fukuoka 812-8581, Japan \\ (Received June 2, 2005 and accepted July 26, 2005)
}

\begin{abstract}
Treatments with indole-3-acetic acid (IAA) at $0.1 \%(\mathrm{w} / \mathrm{w})$ in lanolin paste to the cut surface of the top internode of excised stem from growing shoots of cooled tulip (Tulipa gesneriana L. cv. Apeldoorn) bulbs greatly promoted the growth of all internodes of the stem. In control stems treated with lanolin only in the same way as IAA application, the stem growth was very small. The fresh weight of the stems treated with IAA was much higher than that of the untreated stems, but the total dry weight of the stems of both treatments was similar. Dry weight of the first internode substantially decreased with IAA, whereas that of the upper internodes increased. On the basis of dry weight of different internodes of untreated and IAA treated stems it is evident that carbohydrates occurring in the first (basal) internode are utilized for the growth of the upper internodes especially the third and fourth (top) internodes with auxin.
\end{abstract}

\section{INTRODUCTION}

In tulip plants elongation growth of stems and development of the leaves are well known to be due to almost entirely elongation of cells produced during earlier developmental stages (Gilford and Rees, 1973). Elongation growth of the tulip stem has been reported to be controlled by auxin provided by the leaves and gynoecium, since removal of all leaves and flower bud almost fully inhibited the growth and the application of auxin recovered the suppression of stem growth (Op den Kelder et al., 1971; Hanks and Rees, 1977; Okubo and Uemoto, 1985; Okubo et al., 1986). Saniewski and De Munk (1981) and Banasik and Saniewski (1985) also showed that elongation of all internodes in cooled tulip bulbs is strikingly promoted by the application of auxins where the flower bud was removed from the shoot with the absence of leaves, supporting the important role of gynoecium for auxin source. These studies were, however, conducted with the stems with their basal plate, scales and roots attached. It is possible that nutrition, carbon source and plant hormones supplies from these organs may affect the stem growth induced by auxin. In this study, the effects of auxin (indole-3-acetic acid, IAA) on stem growth of tulips were studied using stem segments excised from growing shoot to eliminate the effects of other organs.

1 Research Institute of Pomology and Floriculture, Pomologiczna 18, 96-100 Skierniewice, Poland

2 Department of Biological Science, Graduate School of Science, Osaka Prefecture University, 1-1 Gakuen-cho, Sakai, Osaka 599-8531, Japan

* Corresponding author (E-mail: msaniew@insad.pl) 


\section{MATERIALS AND METHODS}

Tulip (Tulipa gesneriana L. cv. Apeldoorn) bulbs with circumference of $10-11 \mathrm{~cm}$, after lifting, were stored at $17-20^{\circ} \mathrm{C}$ until October 15 , and then dry-cooled at $5^{\circ} \mathrm{C}$ until planting. The bulbs were planted individually in pots and cultivated at a temperature of $17-20^{\circ} \mathrm{C}$ in a greenhouse under natural light conditions. Shoots of different length, 6.1 and $12.1 \mathrm{~cm}$ in average, from the growing tulips were excised at the basal plate, and then all leaves and flower bud were removed from the shoots. In the place of removed flower bud lanolin only (control) or lanolin containing IAA at a concentration of $0.1 \%(\mathrm{w} / \mathrm{w})$ was applied and the stems were kept in water in the greenhouse at a temperature of $17-20^{\circ} \mathrm{C}$ in natural light conditions. Ten stems per treatment were used. The lengths of the internodes were measured every two days and when the stems had reached their final length, and fresh and dry weights of each internode were also measured. Experiments were repeated three times.

\section{RESULTS AND DISCUSSION}

In control stem segments treated with lanolin only the stem growth was very small and earlier senescence represented by the loss of chlorophyll was observed (data not shown) as well as the case of the stem growth of tulips with bulbs, which all leaves and flower bud were excised as reported previously (Saniewski and De Munk, 1981). On the

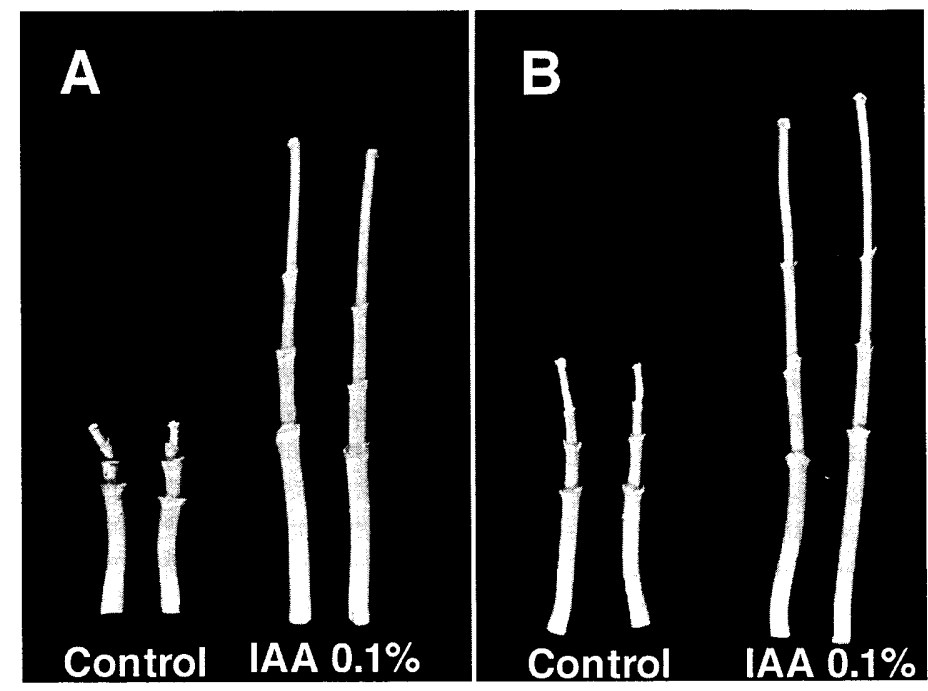

Fig. 1. Effect of IAA on growth of stem segment excised from growing shoots of cooled tulip bulbs; IAA at concentration of $0.1 \%(w / w)$ in lanolin was applied on the top internode of the stem. A) initial length of the stem $-6.1 \mathrm{~cm}$, experiment made on January 26 , photographed on February 3. B) initial length of the stem $-12.1 \mathrm{~cm}$, experiment made on January 26, photographed on February 3. 


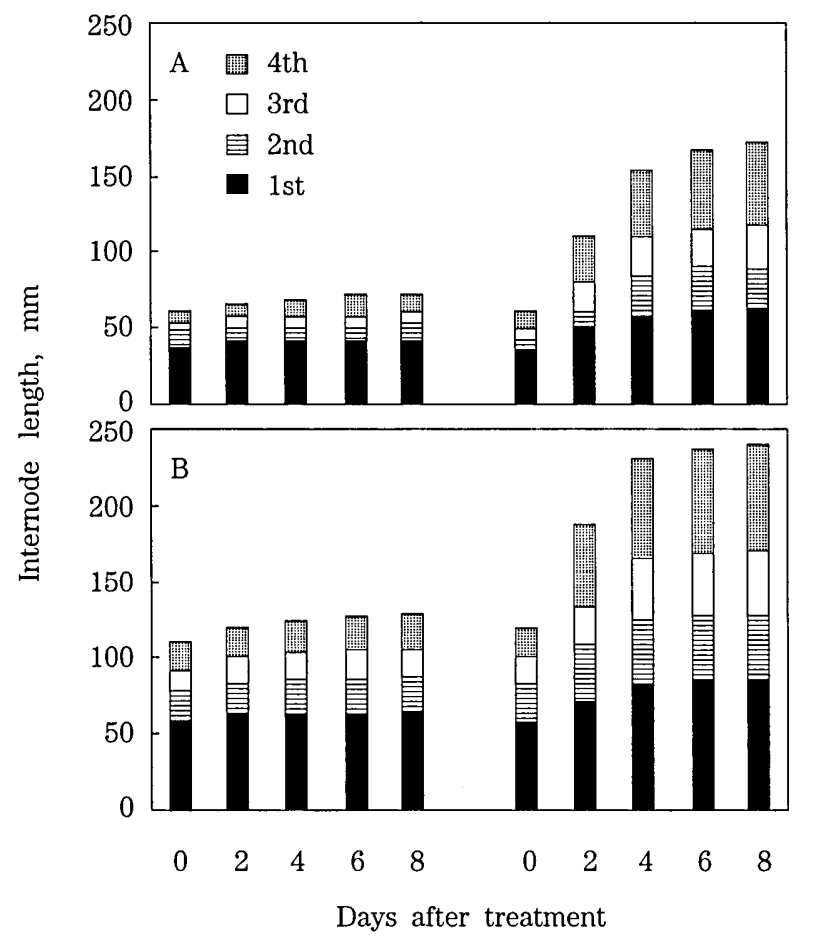

Fig. 2. Dynamics of growth. of stem segment excised from growing shoots of cooled tulip bulbs after treatment with IAA $(0.1 \%$, $\mathrm{w} / \mathrm{w}$, in lanolin) on the top internode of the stem; experiment made on January 26 (see Fig. 1). A) initial length of the stem $-6.1 \mathrm{~cm}$, experiment made on January 26 . B) initial length of the stem $-12.1 \mathrm{~cm}$, experiment made on January 26 .

other hand, the application of IAA as a lanolin paste at the cut surface of flower bud in excised stems extremely promoted the elongation growth in both cases that the initial lengths were about 6 and $12 \mathrm{~cm}$ (Figs. 1 and 2). In the segment with the initial length of about $6 \mathrm{~cm}$, the lengths of the first and top internodes were finally 1.7 and 6.1 times longer than their initial lengths, respectively (Fig. 2A). In the segment with the initial length of about $12 \mathrm{~cm}$, the lengths of the first and top internodes were also 1.5 and 4.8 times longer than their initial lengths, respectively (Fig. 2B). Promotive effect of IAA on growth of stem segments in which all leaves and flower bud with or without bulb were removed has been more conspicuous (Saniewski and De Munk, 1981; Banasik and Saniewski, 1985). These results suggest that excised stem alone is still capable to elongating in response to IAA, while basal plate, scales and roots somehow contribute to IAA-induced stem growth of tulips.

More conspicuous IAA-induced elongation was found in the top, fourth, internode in both segments with initial length of about 6 and $12 \mathrm{~cm}$, as compared with that in the first 
to third internodes (Fig. 3), indicating that young internode is highly responsible to IAA. This observation was almost same as in tulip shoots only without flower bud (Saniewski and De Munk, 1981; Banasik and Saniewski, 1986; Saniewski and Wegrzynowicz-Lesiak, 1993). Total elongation of stem segment was slightly larger in the segments with the initial length of $12 \mathrm{~cm}$ than that with the initial length of $6 \mathrm{~cm}$. These results suggest the basal region of stem segments also contribute to IAA-induced elongation growth of the stem segments as a source of materials for growth.

Similar to the stem length, fresh weight of the stems treated with IAA was much higher than that of the untreated stems (Fig. 4). The promotion of IAA on fresh weight of each internode was almost coincided with that on internode length, indicating that IAA is responsible for longitudinal elongation growth but not swelling.

Differently from the effect of IAA on length and fresh weight of stem segment, little
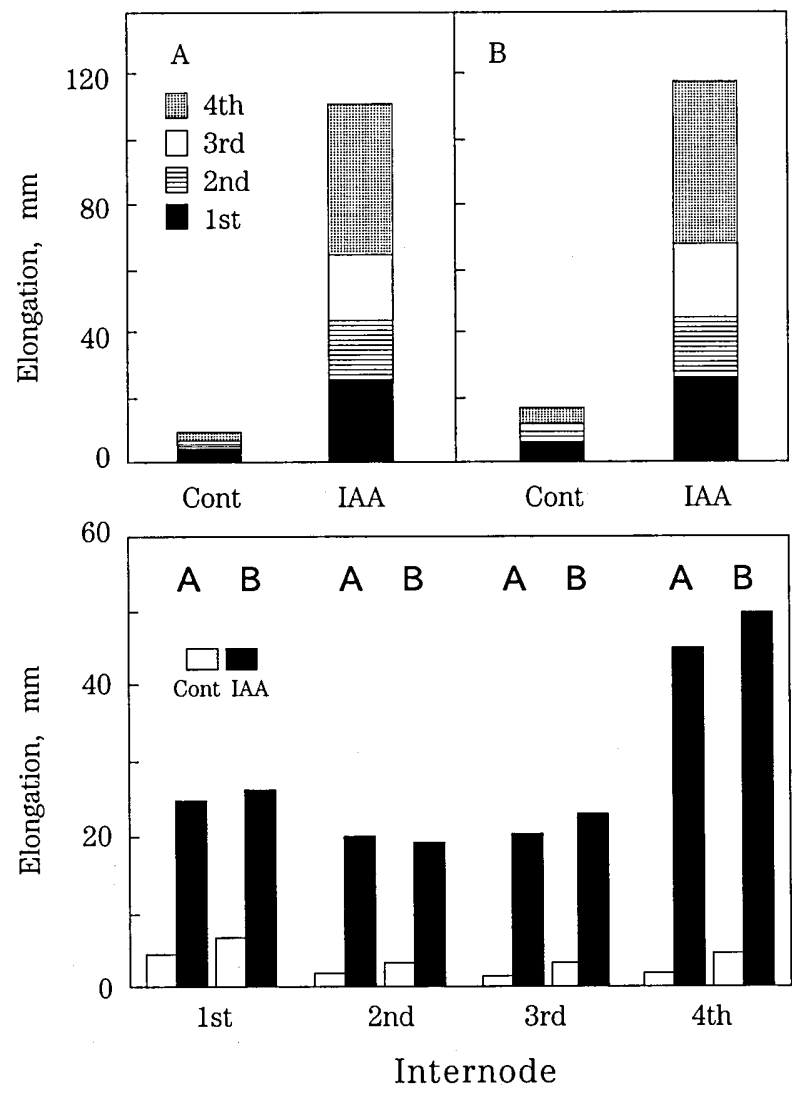

Fig. 3. Effect of IAA on elongation of each internode of stem segment prepared from growing shoots of cooled tulip bulbs. A) initial length of the stem $-6.1 \mathrm{~cm}$, experiment made on January 26. B) initial length of the stem $-12.1 \mathrm{~cm}$, experiment made on January 26 . Measurements were made on February 3. 


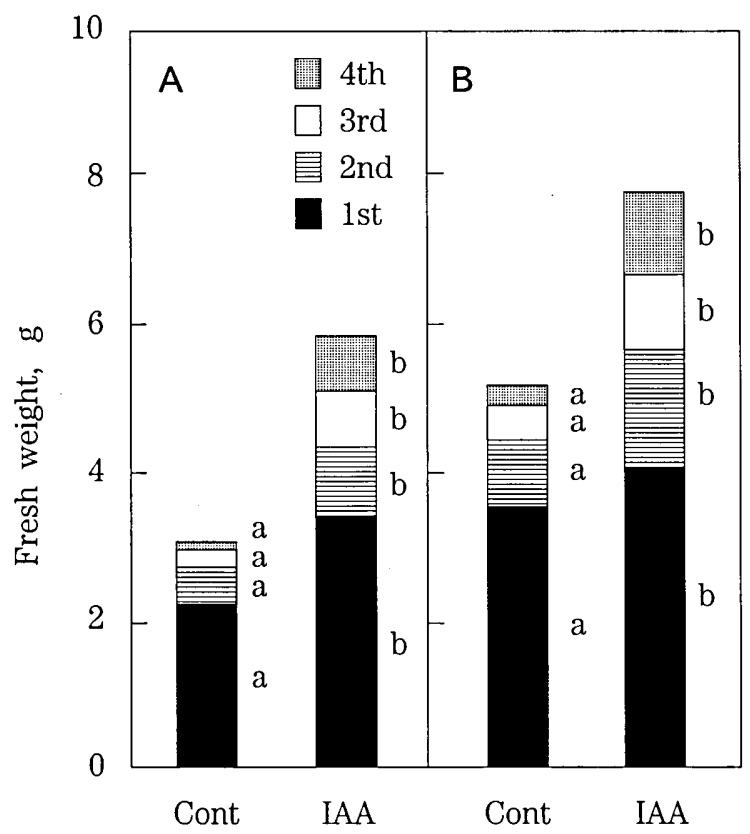

Fig. 4. Effect of IAA on fresh weight of each internode of the stem segment excised from growing shoots of cooled tulip bulbs; IAA at concentration of $0.1 \%$ $(w / w)$ in lanolin was applied on the top internode of the stem; experiments made on January 26 and measurements of the weight on February 3 (see Figs. 1 and 2). A) initial length of the stem $-6.1 \mathrm{~cm}$. B) initial length of the stem $-12.1 \mathrm{~cm}$. a, b: Mean separation in each internode by Duncan's multiple range test at $5 \%$ of significance.

effect of IAA was found on total dry weight of the stem segment (Fig. 5). Interestingly, three times increase in the dry weight in the top internode of the segment treated with IAA was observed in the segment with the initial length of $6 \mathrm{~cm}$. In the first internode, however, the dry weight decreased with the application of IAA (Fig. 5A). The similar result was also observed in the stem segment with the initial length of $12 \mathrm{~cm}$ (Fig. 5B). These results strongly suggest that IAA-induced growth of excised stem segments of tulips is mainly due to water uptake in each internode of the segment.

Analysis of the distribution in materials calculated by dry weight in each internode of the segment revealed that the amount of IAA-enhanced decrease in dry weight found in the first internodes was balanced with that of IAA-enhanced increase in the upper internodes (Fig. 6). IAA-enhanced increase in dry weight in the fourth, actively elongating internode, was larger in the stem segment with the initial length of $12 \mathrm{~cm}$ than that with the initial length of $6 \mathrm{~cm}$. This strongly suggests that exogenously applied IAA 


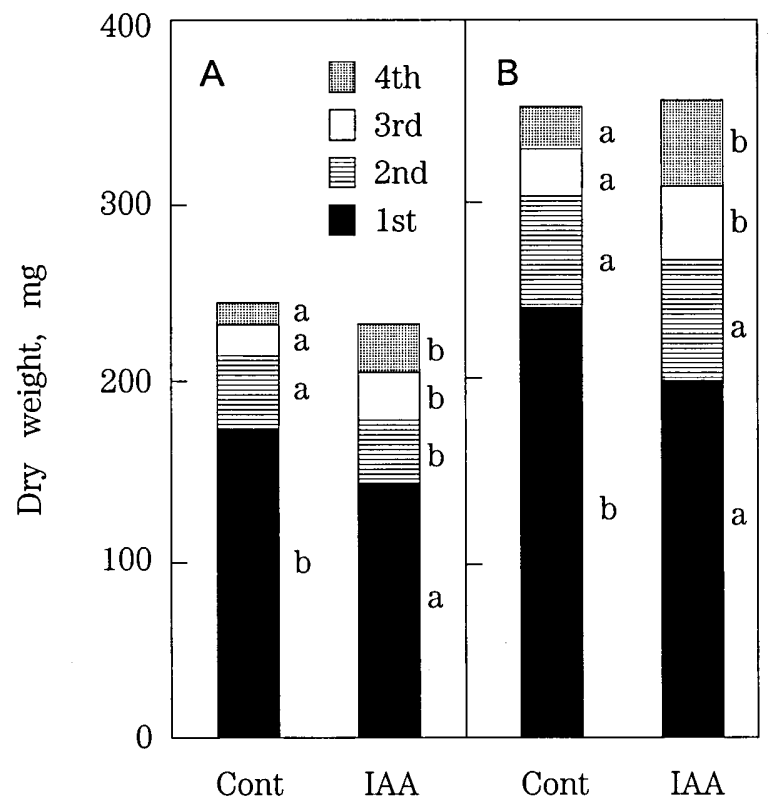

Fig. 5. Effect of IAA on dry weight of each internode of the stem segment excised from growing shoots of cooled tulip bulbs; IAA at concentration of $0.1 \%$ (w/w) in lanolin was applied on the top internode of the stem; experiments made on January 26 and measurements of the weight on February 3 (see Figs. 1 and 2). A) initial length of the stem $-6.1 \mathrm{~cm}$. B) initial length of the stem $12.1 \mathrm{~cm}$. a, b: Mean separation in each internode by Duncan's multiple range test at $5 \%$ of significance.

enhances translocation of solutes from basal region to the upper elongating region of the shoot, and the source size of solutes is responsible to IAA-induced elongation growth. Similar correlation between elongation growth and solute translocation has been demonstrated in etiolated pea epicotyls in relation to gibberellin action on osmoregulation (Miyamoto and Kamisaka, 1990; Miyamoto et al., 1992). On the basis of dry weight of different internodes it is clear that carbohydrates occurring in the first (basal) internode are utilized for the growth of the third and fourth (top) internodes induced by auxin. It is well known that fructans, starch and sucrose are the main storage carbohydrates in the bulb scales of tulips (Moe and Wickstrom, 1973; Thompson and Rutherford, 1977), and in the tulip leaves, glucose, fructose, sucrose, xylose, stachyose, myo-inositol, tuliposides A and B, and traces of arabinose were found (Rutter et al., 1977). Mobilized carbohydrates in tulip bulbs are utilized for the shoot. Sucrose was found to be main mobile leaf assimilate in tulips (Ho and Rees, 1975) and probably is also a mobile sugar during shoot 


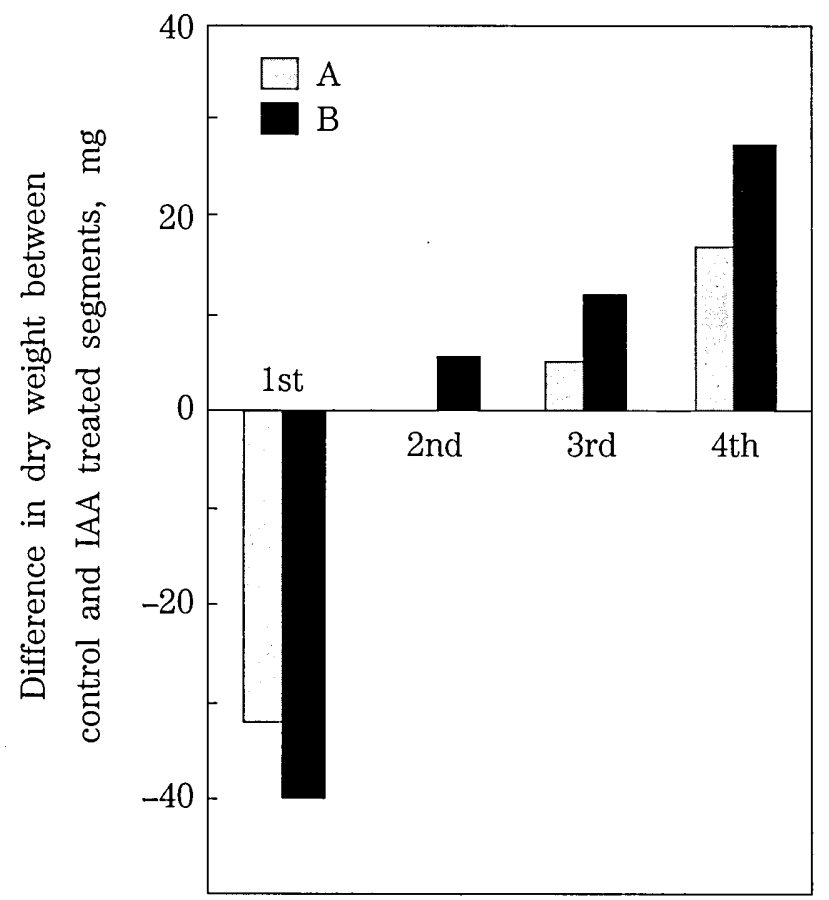

Fig. 6. Changes in dry weight in each internode of the stem segment treated with IAA. Stem segments were excised from growing shoots of cooled tulip bulbs. IAA at concentration of $0.1 \%(\mathrm{w} / \mathrm{w})$ in lanolin was applied on the top internode of the stem. Experiments were made on January 26 and measurements of the weight on February 3 (see Figs. 1 and 2). A) initial length of the stem $-6.1 \mathrm{~cm}$. B) initial length of the stem $-12.1 \mathrm{~cm}$.

growth. It is unclear which carbohydrates are responsible for osmoregulation in excised tulip stems. Further studies of IAA on osmoregulation and translocation of solutes will be required.

As described above, IAA substantially induced elongation growth of the first internode of stem segments. Similar observation is also found in that of the second and the third internodes. However, IAA enhanced the decrease in dry weight in the first internode and little affected dry weight in the second and the third internodes (Figs. 3 and 5), suggesting that IAA also affects mechanical properties of cell walls in each internode of tulip stems. Based on the results of increasing dry weight in the fourth internode and decreasing in the first to third ones (Fig. 6) together with the report that limiting factor during cell elongation induced by IAA is the entry rate of solutes in tissues rather than the rate of solute uptake (Stevenson and Cleland, 1981), active growing 
internode of tulip stems seems to be controlled by both changes in cell wall mechanical properties and osmoregulation caused by enhanced solute translocation. For the analysis of the mechanism of IAA inducing the elongation of tulip shoots, determination of mechanical properties of cell walls as well as osmotic properties in tulip shoots will be also required in further investigation.

\section{REFERENCES}

Banasik, L. and M. Saniewski 1985 The effect of different auxins on tulip stalk elongation. Acta Hort., 167: $193-204$

Gilford, J. McD. and A. R. Rees 1973 Growth of the tulip shoot. Scientia Hortic., 1: 143-156

Hanks, G. R. and A. R. Rees 1977 Stem elongation in tulip and narcissus: the influence of floral organs and growth regulators. New Phytol., 78: 579-591

Ho, L. C. and A. R. Rees 1975 Aspects of translocation of carbon in the tulip. New Phytol., 74: 421-428

Miyamoto, K. and S. Kamisaka 1990 Effect of gibberellic acid on epicotyl growth and carbohydrate distribution in derooted Pisum sativum cuttings with or without cotyledons. Physiol. Plant., 80: 357-364

Miyamoto, K., J. Ueda and S. Kamisaka 1992 Sugar accumulation in growing subhooks of etiolated Pisum sativum seedlings - Stimulation of sugar exudation and invertase activity in epicotyls by gibberellic acid. Physiol. Plant., 84: 106-112

Moe, R. and A. Wickstrøm 1973 The effect of storage temperature on shoot growth, flowering and carbohydrate metabolism in tulip bulbs. Physiol. Plant., 28: 81-87

Okubo H. and S. Uemoto 1985 Changes in endogenous gibberellin and auxin activities during first internode elongation in tulip flower stalk. Plant Cell Physiol., 26: 709-719

Okubo H., S. Shiraishi and S. Uemoto 1986 Factors controlling elongation of the last internode in tulip flower stalk. J. Jap. Soc. Hort. Sci., 55: 320-325

Op den Kelder, P., M. Benschop and A. A. De Hertogh 1971 Factors affecting floral stalk elongation of flowering tulips. J. Amer. Soc. Hort. Sci., 96: 603-605

Rutter, J. C., W. R. Johnson and C. W. Willmer 1977 Free sugars and organic acids in the leaves of various plant species and their compartmentation between the tissues. J. Exp. Bot., 28: 1019-1028

Saniewski, M. and W. J. De Munk 1981 Hormonal control of shoot elongation in tulips. Scientia Hortic., 15: 363-372

Saniewski, M. and E. Wegrzynowicz-Lesiak 1993 Continuous supply of auxin is necessary for tulip stem growth. J. Fruit Ornamental Plant Res., 1: 59-66

Stevenson, T. T. and R. E. Cleland 1981 Osmoregulation in the Avena coleoptile in relation to auxin and growth. Plant Physiol., 67: 749-753

Thompson, T. and P. P. Rutherford 1977 Morphological development and carbohydrates changes of forced tulips. J. Hort. Sci., 52: 9-17 